\title{
Field studies of estuarine turbidity under different freshwater flow conditions, Kaipara River, New Zealand
}

\author{
Steven B Mitchell ${ }^{1}$, Malcolm O Green ${ }^{2}$, Iain T MacDonald ${ }^{2}$, Mark Pritchard ${ }^{2}$ \\ ${ }^{1}$ School of Civil Engineering and Surveying, University of Portsmouth, PO1 3AH, UK \\ ${ }^{2}$ National Institute of Water and Atmospheric Research (NIWA), Hamilton, New Zealand
}

\begin{abstract}
We present a first interpretation of three days of measurements made in 2013 from the tidal reaches of the Kaipara River (New Zealand) under both low and high freshwater inputs and a neap tidal cycle. During the first day, we occupied two stations that were approximately $6 \mathrm{~km}$ apart in a tidal reach that runs for $25 \mathrm{~km}$ from the river mouth to the upstream limit of tidal influence. During the second day, longitudinal surveys were conducted over a distance of $6 \mathrm{~km}$ centred on the upstream station. The data reveal a turbidity maximum in the form of a high-concentration 'plug' of suspended mud that was advected downstream on the ebbing tide past the upper (HB) measurement station and which exchanged sediment with the seabed by settling at low slack water and by resuspension in the early flooding tide. The data suggest that fine sediment is transported landwards and trapped in the upper part of the tidal reach under these low-flow conditions. On the third day of measurements we repeated the experiments of the first day but later in the year, for a much higher freshwater flow. This interpretation of our data set highlights the potential contribution of a range of processes to the generation of the observed suspended-sediment signals, including resuspension of local bed sediment, advection by the tidal current, settling of suspended sediment over a long timescale compared to the advection timescale, advection of longitudinal gradients in suspended sediment, and suppression of vertical mixing by density stratification of the water column. The level of temporal and spatial detail afforded by these measurements allows a much clearer understanding of the timing and importance of vertical stratification on the transport of suspended particulate matter than is generally possible using fixedpoint sensors.
\end{abstract}

\section{Introduction}

Estuaries are commonly centres of population and commerce. The availability of water, access to trade routes and to points further inland, and sources of food and materials mean that the careful management of estuaries is central to economic growth and development. Of particular concern are the effects of human activities on the natural functioning of estuaries and the services that they provide. The dredging of channels and the management of muddy intertidal regions both require an understanding of the physical processes that govern the transport of fine sediments in regions that can be some distance away from the open sea where the adjacent coastline is subject to a high tidal range (Wu et al., 2004; Schuttelaars et al., 2013; de Jonge et al., 2014). In some cases, canalisation and land reclamation over several centuries have forced estuaries to form within long tidal rivers, subject to the influences of the processes that occur at the freshsaltwater interface (Uncles and Stephens, 1993). When such systems are subject to stressors such as increased sediment loading, drought, and freshwater abstraction, this can affect the balance of processes controlling sediment erosion, transport and deposition, all of which need careful management. The presence 
of high concentrations of suspended material can also adversely affect primary production via reduced light penetration (Obrador \& Pretus, 2008; Pedersen et al., 2012). Here, we focus on the response of the turbidity maximum in a narrow, shallow system subject to the influences of the fresh-saltwater interface and increased inputs of fine sediment from the landward side. As with all such studies, the provision of good quality data is essential for calibrating numerical models that underpin the decisions made by managers on the long-term sustainability of estuarine systems under rapidly changing environmental conditions.

We present a preliminary interpretation of measurements of a turbidity maximum (TM) from the tidal reach of the Kaipara River, which drains an area to the west of the city of Auckland, on the North Island of New Zealand (Fig. 1a). To our knowledge this is the first report of its kind on the TM-related sediment dynamics of this or any nearby tidal system. The system has much in common with other estuarine systems in New Zealand in that since European colonisation there has been a considerable increase in the amount of sediment it receives from terrestrial sources, which has been primarily due to large-scale catchment deforestation (e.g., McGlone, 1983; Page and Trustrum, 1997), with concomitant increases in estuarine sedimentation rates (e.g., Hume and McGlone, 1986; Goff, 1997; Addington et al., 2007). This data set from the Kaipara river was obtained in early 2013 during a period of prolonged low rainfall, which caused a migration of saline water inland under certain tidal conditions. Apart from the lack of data on this or similar systems, the novelty of this work lies in considering the temporally and spatially varying details of the structure of the salinity and concentrations of suspended material together with the velocity, over depth, in a system subject to the sudden arrival of relatively newly eroded material.

In more general terms it is well known that turbidity maxima are usually highly mobile, both over individual tides and over longer time scales in response to changing patterns of freshwater flow (Doxaran et al., 2009) and sediment input (Jiang et al., 2013). It is also known that the nature and location of the fresh-saltwater interface in a tidal river can influence the transport of fine sediment which then dictates where the TM will be and what form it will take. The magnitude, location and persistence of vertical, saline-induced density gradients affect both the vertical velocity gradient and the net tidal transport of fine material (Geyer, 1993; Liu et al., 2009; Burchard and Hetland, 2010). Both of these can be measured with some precision provided the conditions allow it, and both are affected by the twin drivers - sediment inputs and freshwater runoff of interest here.

Our aim is to understand the extent to which the TM becomes trapped in the tidal reach of the Kaipara River under conditions of low freshwater runoff, and to provide a preliminary assessment of the relative importance of the mechanisms involved in its entrapment and subsequent migration downstream. The data were obtained on three days in 2013, on 19 February, 5 March, and 4 July, when we measured velocity, suspended sediment concentration and salinity in mid-channel over the whole depth of flow at 15-minute intervals through the tidal cycle. On all three days the tide was neap; on the first two days the freshwater runoff was very low, but on the third day the freshwater flow was much higher. Clearly, a numerical model of the type used by many previous authors would be useful in isolating the mechanisms involved, but by using high-resolution spatial and temporal measurements it is possible to visualise the processes involved more clearly than would be possible using any of the available models in this previously unexplored tidal system.

We first present a brief review of the literature on the complex interplay between turbidity maxima and the fresh-saltwater interface in a number of systems where measurements have been undertaken previously. We then give details of our field campaigns and study site, present and discuss some results, and end with our main conclusions to date. 


\section{Turbidity maxima and the fresh-saltwater interface}

Over the past few decades a number of studies have been published describing the behaviour of turbidity maxima in a range of estuaries (Fettweis et al., 1998, Uncles et al., 1994; Uncles et al., 2006; Garel et al., 2009). Previous studies of TM dynamics can be divided into two categories, addressing (1) the long-term migration of TMs and their response to forcing factors of tides and freshwater inputs, and (2) the processes that occur during individual tidal cycles. In any understanding of systems as a whole, or in order to calibrate numerical models, both types of study are important because of the wide range of time scales over which TMs persist and migrate.

It is well known that estuaries with tidal ranges between approximately 2 and $4 \mathrm{~m}$ and with relatively modest freshwater inputs vary between being well-mixed at some times and stratified at others (Li et al, 2016). Importantly, the degree and persistence of stratification inhibits the vertical transfer of momentum, leading to the suppression of turbulence and mixing (Burchard and Hetland, 2010). This can in turn suppress the vertical movement of sediment upwards into the main flow, which implies less horizontal transport by tidal currents. The degree of salinity stratification is known to vary depending on location, the state of the tide, the tidal range, and the freshwater input. Thus, a tidal system can be quite well stratified with respect to salinity at the downstream end, but quite well mixed further upstream, even though the salinity may not itself be that low. Over the course of a given tide, the degree of stratification may also vary.

An ongoing debate concerns the relative importance of the different mechanisms that generate turbidity maxima and cause sediment to become trapped in estuaries. It is clear that gravitational circulation, tidal pumping, different manifestations of tidal asymmetry, and settling and scour lags all have a role to play (Mitchell et al., 1998; Wai et al., 2004; Dyer et al., 2004; Chernetsky et al., 2010). The predominance of one or other of these mechanisms depends on the characteristics of the system in question (Warner et al., 2007). The matter of storage and sequestering of sediments (Mitchell et al, 2003; Deloffre et al, 2006) must also be addressed in that in some cases material is deposited over individual tidal cycles on intertidal flats or on the subtidal bed, or material may remain permanently suspended, generating a highly mobile pool of fine sediment. The effects of vertical spiral flows (Wu et al., 2012), flocculation (Xu et al., 2010) and sediment source in TMs (Savoye et al., 2012) have also been shown to affect the trapping efficiency of sediments in turbidity maxima.

The location and magnitude of the TM changes in response to freshwater input. Among the many works documenting the flushing of TMs downstream and their subsequent slower migration back upstream are, for example, those of Grabemann and Krause (1989) and Mitchell et al. (2012). Green and Hancock (2012) documented the flushing of saline water entirely from a small New Zealand tidal creek during periods of high freshwater runoff. In view of the importance of freshwater flow, one central question must relate to the response of tidal systems when the freshwater flow is severely reduced as, for example, when an estuarine barrage is constructed (Capo et al., 2009), there is freshwater abstraction further upstream, or (as here) where the flow in the river falls to a consistently low value because of drought, then increases again due to large amounts of rainfall. Data describing and quantifying responses of the sediment regime under these conditions are scarce, especially data that have sufficient temporal and spatial resolution to allow the complex balance of flow and sediment processes to be properly understood. If successful, long-term approaches of this kind can lead to a detailed understanding of the response of major estuaries (Jalon-Rolas et al, 2015), and can enable long-term estimates of along-estuary suspended sediment flux (Sommerfield and 
Wong, 2011), even taking into account the influence of cross-channel (lateral) variations on the flux (McSweeney et al, 2016)

Our understanding of TM processes generally comes from observation of vertical profiles of suspended sediment concentration (SSC), including how these vary over time at a given location. Li et al (2016) highlighted the importance of a proper understanding of vertical profile data to predict the fate of suspended material in the North Passage of the Changjiang estuary, enabling them to identify areas where tidal pumping was dominant. Vertical profiles of SSC may conform to the standard Rouse model, indicating that sediment in suspension derives from a balance between local vertical mixing and sediment settling under gravity. Other patterns in the SSC profile are indicative of the contribution of other processes including, for example, the advection of a horizontal gradient in SSC (e.g., Bass et al., 2002). Seen over a complete tidal cycle, time-varying SSC profiles can capture the arrival of an advected mobile 'plug' of suspended material, some of which might remain permanently in suspension throughout the tidal cycle, giving an indication of the location of the TM at any given time and the nature of its response to the hydrodynamics. Only by detailed surveys of whole tidal cycles can the balance amongst these various processes be understood. The results of these studies can then be supplemented by data from continuous monitors that can be left to record autonomously for long periods (e.g., Mitchell et al., 2012).

\section{Study Site \& Methods}

The Kaipara River at the centre of the present study drains an area of $267 \mathrm{~km}^{2}$ and has a mean annual freshwater flow rate $Q_{\mathrm{f}}$ of $4.8 \mathrm{~m}^{3} / \mathrm{s}\left(93 \mathrm{~m}^{3} / \mathrm{s}\right.$ annual flood, $277 \mathrm{~m}^{3} / \mathrm{s}$ maximum flood) at the point at which it discharges into the tidal Kaipara river. The catchment is predominantly rural. The town of Helensville (pop. 2500, see www.stats.gov.nz), where there are small wharves providing access to the river, is situated approximately $7 \mathrm{~km}$ from the mouth as the crow flies, or approximately $10 \mathrm{~km}$ measured along the river. Our two measurement sites Kaipara Wharf (KW) and Helensville Bridge (HB) straddle Helensville, being located at $6.6 \mathrm{~km}$ and $11.8 \mathrm{~km}$, respectively, along the river from the mouth. What we consider to be the approximate location of the limit of tidal activity is a further $13 \mathrm{~km}$ upstream of HB, at the Wharepapa Road Bridge.

We conducted three day-long experiments, on 19 February, 5 March, and 4 July, all 2013. The tide range in the southern Kaipara Harbour on 19 February was 1.25 m, which was a neap tide, and on 5 March it was 2.0 $\mathrm{m}$. On 4 July it was $1.85 \mathrm{~m}$. Tides in this area are semidiurnal. The spring tidal range at the same site is 3.0 $\mathrm{m}$. At high tide on 19 February the water depth at $\mathrm{KW}$ was about $6 \mathrm{~m}$ and the low-tide water depth was about $4 \mathrm{~m}$. At HB, the high-tide depth was about $4 \mathrm{~m}$ and the low-tide depth was $2 \mathrm{~m}$. We feel that the detail of the propagation of the tidal signal experienced in this section of the river are beyond the scope of this article, nevertheless these results seem to imply a slight tidal amplification (e.g., Friedrichs and Aubrey, 1994) between the wider estuary and the KW site. Due to safety considerations (principally the need to work during daylight hours) the July deployment only lasted 6.5 hours, covering the ebb and the start of the flood tide only, rather than the full tidal cycle of the February/March deployments.

On the first two days (19 February and 5 March) the freshwater flow was very low, $0.1 \mathrm{~m}^{3} / \mathrm{s}$ (see Fig. 2). This followed a period of exceptionally low rainfall across much of the country. The catchment responds rapidly to rainfall, with flow in the river responding within a few hours to individual rainfall events, as also illustrated by the three months of flow data shown in Fig. 2. There is no record of freshwater flow on 4 July but it is estimated at about equivalent to the long term average of $4.8 \mathrm{~m}^{3} / \mathrm{s}$. Along the tidal creek, including between KW and HB, the banks were covered in a thick layer of fine sediment, and the width of the channel 
along the reach of interest varies in the range 10-15 m. The deployment sites were bordered by steep muddy banks topped by high intertidal flats covered with mangroves, making the channel well protected from the effects of wind.

The deployments were boat-based, and made use of two small survey craft with instrumentation mounted on them which could be lowered gradually into the water in order that water-column profiles in key parameters of SSC, conductivity and temperature could be measured. The instruments consisted of a DOBIE wave and tide gauge fitted with a depth (pressure) sensor and a Seapoint optical backscatter sensor (OBS) for measuring SSC, and two conductivity-temperature-depth (CTD) probes (one Seabird SBE 19 and one RBR Instruments XR-620). On both days we took measurements over the complete tidal cycle, from high water to the next high water. On 19 February two bottom-mounted ADCPs were deployed, one at each site, to measure current velocity profiles over the tidal cycle. On 5 March, a single small boat fitted with a boatmounted, downward-looking ADCP was used to obtain current velocity profiles at various positions either side of $\mathrm{HB}$, from $+2 \mathrm{~km}$ (downstream of $\mathrm{HB}$ ) to $-5 \mathrm{~km}$ (upstream of HB). As on 19 February, OBS and CTD sensors were periodically lowered from the side of the boat. Access to and from the river was via a slipway adjacent to the site at $\mathrm{KW}$.

During the deployment, the instruments at KW and HB were lowered over the side of the boat(s) at the same time at 15-min intervals. The lower-raise-lower-raise cycle lasted about 3 minutes and readings were taken every second. Hence, over a typical dip we obtained around 180 readings of depth, conductivity, temperature and optical backscatter. Readings of conductivity and temperature were converted to salinity (quoted here without units and measured using the practical salinity scale). Every two hours, surface water samples were collected and these were later subjected to gravimetric analysis to develop an approximate linear correlation between optical backscatter in $\mathrm{mV}$ and SSC in $\mathrm{mg} / \mathrm{l}$ of $1 \mathrm{mV}=1 \mathrm{mg} / \mathrm{l}$ (data not shown). Despite the well known difficulties involved in the use of a direct linear correlation (e.g., Bunt et al., 1999) we felt that it was useful to make this blanket assumption in the interests of obtaining a general picture of the variations in sediment transport over the three tidal cycles and making progress in understanding the quantities of suspended material involved.

\section{Results}

The main results obtained from the first deployment (19 February) are shown in Figs. 3 and 4. These show the variations with both time and depth over the whole tidal cycle of current velocity (upper panel), salinity (middle) and SSC (lower) at sites KW (Fig. 3) and HB (Fig. 4). Positive current velocity (yellow shade) denotes down-estuary (seawards) flow, and negative (purple shades) denotes up-estuary (landwards) flow. The salinity and current speed were generally higher at KW compared to at HB, while the SSC was higher at HB.

The water column at KW towards the end of the ebb tide was vertically stratified with respect to both current velocity and salinity (Fig. 3). The lower salinity water at the surface flowed seawards while the denser, more saline water near the bed was virtually stationary for much of the time. At the same time, the SSC was virtually zero, indicating that the upstream and local bed material were either non-erodible or had already been eroded to a depth where the bed shear stress was less than the critical bed shear stress for initiation of motion, and sediment eroded previously during the tidal cycle had transited the measurement site. 
Comparing results for the same period at HB (Fig. 4) reveals key differences in the vertical structure of the water column over the tidal cycle. Firstly, at the shallower HB site, both the velocity and salinity profiles were uniform during the late ebb. Secondly, a 'plug' of very high SSC arrived towards the end of the ebb tide (hours 10-11), which had a mud concentration 4-5 times higher than the SSC observed at the same time at the $\mathrm{KW}$ site. We suggest that the appearance at $\mathrm{HB}$ of the plug is the manifestation of a turbidity maximum, advected downstream to the HB measurement site from further upstream by the ebb-tidal currents. It is noteworthy that the plug of material largely disappears at low slack water (hour 12), presumably as it (at least partially) settles to the bed. Also noteworthy is the fact that the high concentrations of suspended mud do not clearly reappear after low water, although some resuspension of this material appears to be evident (hours 13-14), which is transported landwards during the early part of the flood tide. The longitudinal gradient in salinity is interesting to note in relation to the location of the inferred turbidity maximum in that under these low freshwater flow conditions, the TM is located in the low-salinity (0-10) zone.

A summary of the results from the deployment of 5 March is shown in Fig. 5, which displays longitudinal profiles of depth-mean salinity and SSC. The longitudinal profiles are referenced to distance from site HB (negative is downstream of HB; positive is upstream of HB). Although full depth profiles were obtained on 5 March, here we only show the depth-mean values for clarity, and note that there was no real difference in the 5 March patterns of velocity, salinity and SSC compared to 19 February. As in Fig. 4(c), the longitudinal profiles show the arrival of a plug of high SSC arriving at site HB late in the ebb tide. Fig. 5 also shows the longitudinal distribution of salinity and SSC around the approximate location of the TM at the HB site. As for the $19 \mathrm{Feb}$ deployment, the vertical salinity gradient was most pronounced during the ebb tide, and mostly disappeared altogether landwards of the HB site (vertical gradient not shown).

It is instructive to combine the data from both deployments in a single figure to show the relationship between depth-mean current speed and depth-mean SSC (Fig. 6). We used depth-mean velocity (rather than near-bed) because such data are relatively easy to obtain and the result can help us better understand the nature of the relationships involved. Because the 5 March deployment involved taking measurements at a number of locations centred on the HB site, here we use all the measurements taken within a distance of 2 $\mathrm{km}$ of HB to represent conditions at that site. Fig. 6 reveals a highly nonlinear relationship between current speed and SSC at both sites, which is to be expected, but with an asymmetry between flood and ebb tide at site HB (Mitchell et al., 1998) showing a different response of SSC to current speed on the ebb tide compared to on the flood tide. Given the intermittent vertical stratification of the water column, the depthmean current speed may not be a good indicator of the shear stress exerted on the bed by the tidal current (e.g., Geyer, 1993). It is useful to note that some parts of Fig. 6 do appear to show a linear relationship (e.g., $19 \mathrm{Feb}$, decelerating ebb tide at HB), however, this is hardly surprising in view of the long periods during each tidal cycle where the hydraulic regime can be thought of as quasi-steady (on the preceding accelerating ebb, there is less material available, showing an important hysteresis effect).

Considering the implications of the results in Figure 6 in more detail, on both the flood and ebb tides, the SSC is similar for both sites between 0 to $-20 \mathrm{~cm} / \mathrm{s}$ (flood) and 0 to $20 \mathrm{~cm} / \mathrm{s}$ (ebb). One way to interpret this is that at these low speeds there is no local resuspension, and we are just seeing a uniform "washload". The only evidence of anything different occurring is seen in the ebb data at HB on 19 Feb, suggesting that for this decelerating tide, at this site, there is more than a simple case of local resuspension.

Beyond $-20 \mathrm{~cm} / \mathrm{s}$ on the flood tide the SSC data diverge, and the increment in SSC per increment in current speed (hereafter $\Delta \mathrm{SSC} / \Delta$ speed) is much greater at $\mathrm{HB}$ than it is at $\mathrm{KW}$. This is evidence of a clearly different response at $\mathrm{HB}$ compared to $\mathrm{KW}$. It is not possible to tell whether the same difference in response (i.e., 
between $\mathrm{HB}$ and $\mathrm{KW}$ ) occurs on the ebb tide at current speeds greater than $20 \mathrm{~cm} / \mathrm{s}$ because the $\mathrm{KW}$ data do not exceed this value. The influence of the vertical salinity gradient precludes these higher depth mean velocities for the flood tide at $\mathrm{KW}$.

Comparing flood and ebb responses at each site, at $\mathrm{HB}, \Delta \mathrm{SSC} / \Delta$ speed is very different on the flood tide (speeds beyond $-20 \mathrm{~cm} / \mathrm{s}$ ) compared to on the ebb tide (speeds beyond $20 \mathrm{~cm} / \mathrm{s}$ ). As a result of this (for instance) there is more sediment in suspension at $50 \mathrm{~cm} / \mathrm{s}$ on the ebb tide than there is at $-50 \mathrm{~cm} / \mathrm{s}$ on the flood tide. This asymmetric response (at HB) tells us that the recorded SSC cannot purely be a result of local resuspension and must relate to the availability of material for transport (Uncles et al, 1994).

The net flux of suspended mud per unit width of channel $\left(\mathrm{kg} \mathrm{m}^{-1} \mathrm{~s}^{-1}\right)$ was estimated simply as the product of SSC, current speed and water depth, all of which varied over the tidal cycle (Fig. 7). In fact, the detail of our results enabled us to calculate the fluxes at intervals of $0.5 \mathrm{~m}$ throughout the depth of the water, thus affording us with a depth-integrated value. The cumulative flux was calculated by adding together the fluxes obtained at the 15-minute intervals used during the field work. These values of flux were calculated per unit width, but can be considered a reasonable representation of the along-channel transport, given the relatively narrow channel. Over the measured tidal cycle (high tide - low tide - high tide) there was a net landward flux of suspended mud at both sites, which is indicative of the transport and trapping of fine sediment in the landward reach of this tidal river under these conditions.

The differences between high and low freshwater flow conditions at the two sites are illustrated by the difference in the ebb-tide velocity profiles shown in each of Figs. 8 and 9. It is instructive to compare Fig. 3(a) with Fig.8(a) and Fig 4(a) with Fig.9(a), where in each case both the magnitudes of the ebb tide flow are greater and the intensity of the ebb tide stratification is slightly less for the higher freshwater flow case. The salinities are, of course also lower in Figs. 8 and 9; what is most interesting, however, is the absence of any obvious pool of high SSC in these cases, the inference being that under high freshwater flow, the TM is located well within the high-salinity zone, in sharp contrast to the low freshwater flow case.

\section{Discussion}

Figs. 3-5 paint a picture of the characteristics of the lower Kaipara tidal river under low freshwater inputs. There is a clear relationship between the tidal state (ebb-slack-flood) and the degree of stratification (or lack thereof) as previously identified by Liu et al (2009), and more recently by Li et al (2016), among many other examples. The figures reveal a longitudinal gradient both in terms of the depth mean salinity and in terms of the degree of vertical stratification with respect to salinity; moving upstream, the influence of the tide decreases and the channel becomes narrower and shallower, meaning that there is less scope for vertical salinity gradients to develop. In common with $\mathrm{Li}$ et al (2016) we therefore believe that these variations in vertical stratification over relatively short distances may be very important in defining areas of likely sediment trapping under certain hydrological conditions. It may also be that the important effect of stratification on suppression of vertical turbulent transport (Geyer, 1993) plays a role here, but it seems unlikely because of the lack of any strong turbidity signal observed at $\mathrm{KW}$ where the vertical stratification is at its strongest. There appears (19 Feb) to be a strong turbidity maximum that was advected from upstream of the HB site on the ebbing tide to somewhere between the HB and KW sites by low slack water, and which exchanged sediment with the seabed by settling at low slack water and by resuspension in the early flooding tide. The interesting effects of flow reversal at depth over the ebb tide at KW shows that for most of the tide, the water moves in a landward direction near the bed; this is a clear candidate for a mechanistic explanation 
of the net tidal landward movement of material and hence trapping of the TM under these freshwater flow conditions.

The sudden and obvious arrival of this plug of material is unusual and we note that other authors have commented on the unusually high concentrations of terrestrial sediments found in New Zealand rivers, probably caused by relatively recent, intensive agroforestry practices (Addington et al 2007). At present, we have limited evidence of what happens in this and other similar systems under high freshwater flow, and whether the material is sufficiently mobile to be 'flushed out' of the system, either into the wider estuary or the open sea. This would have implications for the management of marine sites in terms of the actions needed to protect sensitive estuarine environments following prolonged high flows. A rather different picture of SSC characteristics can be seen (Figs. 8 \& 9) under the high freshwater flow (or high antecedent freshwater flow) conditions of July 2013 (the precise values of freshwater flow are not available for this deployment). In the July deployment, far less sediment is seen suspended in the water compared with February 2013. The values are in fact a whole order of magnitude less at the end of the ebb tide, when the TM appears in the February deployment. From this it is clear that in July the system is in its 'flushed' state, with any of the mobile material having been advected downstream by the high flows experienced prior to this deployment.

Fig. 6 shows a significantly different relationship between current velocity and SSC at site HB under low freshwater flow (more sediment in resuspension for any given current speed) compared with site KW (less sediment in suspension for any given current speed). This points to the importance of sediment provenance and availability in relationships of this kind (Savoye et al, 2012). However, it is not necessarily correct to conclude from this that there is a greater availability of sediment (to be eroded by the tidal current) at HB compared to at KW. For one thing, the mud concentration profiles were either uniform vertically, which is not consistent with the local bed being the source of the suspended sediment (depending on the sediment settling speed), or mud arrived in a mid-water-column high-concentration plug, as described above. The exception, also mentioned above, was hours 13-14, just after low slack water, when the SSC profiles decayed with elevation above the bed, which is more indicative of resuspension of local bed material. As mentioned above, this could be the result of erosion from the bed of material that settled from the presumed TM during low slack water.

Inspection of the velocity profiles at the two sites (Figs 3, 4, 8 \& 9; (a) in each case) reveals some interesting hydrodynamics for this system. Assuming the location of the ADCP measuring point is the same in the two fixed-station experiments (i.e., in February and July), and that the tides were similar, the only difference between the respective velocity profiles is in the freshwater flow. At HB, the ebb currents are faster (and the ebb tide water column is better mixed) in the July deployment than during the low freshwater flows of the February deployment. The converse is true for the flood tides at HB, where the February flood tide is generally better mixed (i.e., the vertical velocity gradients are smaller) than the July flood tide (data not shown). On the other hand, considering the case at $\mathrm{KW}$, the differences between the February and July deployments here are slightly less clear; if anything, the ebb-tide currents are generally faster in July than in February, with slightly better mixed conditions over the late ebb tide in July; in the February deployment at the equivalent tidal state the velocity stratification is still strong. Further evidence of this difference between the two sites may be seen in the salinity profiles (Figs. 3, 4, 87 9; (b) in each case). The vertical salinity gradients at the KW site do not last as long in the July ebb tide as they do in the February ebb tide (at HB the major difference in July is the lack of salinity at this station). Therefore, it seems fair to say that the system 'feels' the effect of high freshwater flow much more keenly at the HB site than at the KW site, implying that the sediment 'plug' is probably flushed downstream of HB quite rapidly and easily, but may move downstream of KW more gradually. Such observations are greatly assisted by the consideration of net 
sediment flux (Sommerfield \& Wong, 2011) where it is instructive to calculate these at different points and over different time scales than that considered in Fig.7, useful though this is in enabling a preliminary understanding of the behaviour of the SSC under low freshwater flows. Ultimately, longer data sets are more useful in this regard (Jalon-Rolas et al, 2015), but any analysis of this kind tends to be less successful in considering the detailed structure of the water column at different points in the tidal cycle.

Another point to note about the velocity profiles relates to the degree of asymmetry in the slack water periods. In all cases the duration of the high water slack period exceeds that of the low slack water period by a factor of some $3: 1$ (taking the $0.1 \mathrm{~m} / \mathrm{s}$ contour as the cut-off velocity). This implies a greater degree of settling at high water than at low water, particularly at the KW station where slack water near the bed lasts most of the ebb tide, regardless of the freshwater flow. This clearly constitutes a mechanism for net upstream sediment transport (provided there is sediment available) given the amount of settling seen at high slack water in the February deployment where the SSC all but disappears at the slack periods. Furthermore, this asymmetry between flood and ebb velocity distribution is relatively unaffected by the higher freshwater flows seen in July, at least at KW, again implying a rapid downstream flushing of sediment following a high freshwater flow event (if it was not rapid, the similar velocity characteristics would tend to act to hold the sediment in place).

This preliminary interpretation of the data highlights the potential contribution of a range of processes to the generation of the observed suspended-sediment signals, including resuspension of local bed sediment, advection by the tidal current, settling of suspended sediment over a long timescale compared to the advection timescale, advection of longitudinal gradients in suspended sediment, and suppression of vertical mixing by density stratification of the water column. To deconstruct the data more fully with the aim of better understanding the sediment dynamics, we believe a numerical process-based model of the system is required. The channel is relatively narrow, and with some reservations it seems that the lateral variations in velocity, salinity and SSC can be ignored, unlike the situation in wider estuaries (McSweeney et al., 2016). We therefore propose that a two-dimensional laterally averaged model would be the most appropriate type of scheme for dealing with the transport of sediment that forms the TM in this case. Part of the future work to be carried out will consist of devising and calibrating a numerical model to better understand the data; the model will also have application to the management of sediment in the tidal reach of the Kaipara River. Additional field experiments will be undertaken under a wider range of conditions, including higher freshwater flow and high tidal range, to expand our understanding of the behaviour of the turbidity maximum under a wider range of conditions. Further to this, though, there is a clear need to place these results in the wider context of other similar systems in order that the relative contribution of different factors can be taken into account in systems subject to tidal and freshwater influences on SSC behaviour. The results presented by Uncles et al (2002) lend support to this important idea that it is only by understanding the behaviour or turbidity in a range of systems that we can build up a process understanding that can be used to construct reliable numerical models.

\section{Conclusions}

Field measurements have revealed the presence of a turbidity maximum in the tidal reach of the Kaipara River under very low freshwater flow conditions. The turbidity maximum takes the form of a highly mobile plug of sediment which is mainly advected back-and-forth along the channel with the flow. It is subject to the influences of settling over high slack water and resuspension with the faster currents of the flood and ebb tide. Our preliminary interpretation of the data suggests that fine sediment is being transported landwards 
and trapped in the upper part of the tidal reach under low freshwater flow conditions, and then being flushed seawards under high freshwater flow, implying a high degree of mobility and a lack of dependence on the location of the low-salinity zone. Further field studies are needed to quantify and characterise both the causes and effects of this phenomenon of high freshwater flow flushing of sediments downstream.

The water in the main channel is subject to a degree of vertical stratification with respect to salinity and with respect to along-channel velocity. These vertical gradients in salinity and velocity appear to increase with distance downstream, and are most pronounced over the early part of the ebb tide, though at the downstream (KW) site, they generally persist over the whole of the ebb, becoming reduced at the late ebb under higher freshwater flow. A fair degree of asymmetry exists in terms of the currents (between ebb and flood tide) and the slack water periods, with high slack water lasting longer than the equivalent low water period under both flow conditions and at both sites; added to the effect of the vertical gradients, this implies a much greater degree of settling of suspended material at high slack water compared with at low slack.

The effects of high freshwater flow are clearly visible in the velocity profiles at the HB station, but are much less obvious at the KW station. This implies that the system is relatively sensitive to downstream flushing of material under high flows at the landward end of the interface between the fresh and saline water, but much less sensitive to flushing at points further downstream, where the velocity profile is controlled by the tide. Because we saw no kind of plug of suspended material at either site under high freshwater flows, this must mean that much of the downstream transport of TM-related material occurs rapidly, in response to one or a few successive freshwater flow events.

It is recommended that the next phase of this research programme should involve building a numerical model of the system to help in data interpretation, and conducting additional field experiments under a wider range of hydrological conditions including spring tides and other nearby systems, to expand our understanding of the behaviour of the turbidity maximum in this and similar systems.

\section{Acknowledgements}

The authors are very grateful to all members of NIWA involved in these field experiments, for their assistance collecting data, especially Mike Townsend, Dave Bremner and Scott Edhouse. We acknowledge funding from the University of Portsmouth, the (New Zealand) Ministry of Business, Innovation and Employment (C01X1005) and the NIWA Freshwater and Estuaries Centre (Catchment to Estuaries core programme, FWCE). The comments of three anonymous reviewers were also enormously helpful in sharpening the focus of this work.

\section{References}

Addington L.D., Kuehl S.A. \& McNinch J.E., 2007. Marine Geology Contrasting modes of shelf sediment dispersal off a high-yield river: Waiapu River, New Zealand 243, 18-30

Bass S.J., Aldridge J.N., McCave I.N. \& Vincent C.E., 2002. Phase relationships between fine sediment suspensions and tidal currents in coastal seas. Journal of Geophysical Research 107 No. C10, 1-14.

Bunt J.A.C., Larcombe P. \& Jago C.F., 1999. Quantifying the response of optical backscatter devices and transmissometers to variations in suspended particulate matter. Continental Shelf Research 19, 1199-1220 
Burchard H. \& Hetland R.D., 2010. Quantifying the Contributions of Tidal Straining and Gravitational Circulation to Residual Circulation in Periodically Stratified Tidal Estuaries. Estuaries. Journal of Physical Oceanography 40, 1243-1262.

Capo S., Brenon I., Sottolichio A., Castaing P. \& Le Goulven P., 2009. Tidal sediment transport versus freshwater flood events in the Konkouré Estuary, Republic of Guinea. Journal of African Earth Sciences 55, 52-57.

Chernetsky A.S., Schuttelaars H.M. \& Talke S.A., 2010. The effect of tidal asymmetry and temporal settling lag on sediment trapping in tidal estuaries. Ocean Dynamics 60, 1219-1241.

de Jonge V.N., Schuttelaars H.M., van Beusekom J.E.E., Talke S.A. \& de Swart H.E., 2014. The influence of channel deepening on estuarine turbidity levels and dynamics, as exemplified by the Ems estuary, Estuarine, Coastal and Shelf Science 139, 46-59.

Deloffre J., Lafite R., Lesueur P., Verney R., Lesourd S., Cuvilliez A. \& Taylor J., 2006. Controlling factors of rhythmic sedimentation processes on an intertidal estuarine mudflat - Role of the turbidity maximum in the macrotidal Seine estuary, France. Marine Geology 235, 151-164.

Doxaran D., Froidefond J.-M., Castaing P. \& Babin M., 2009. Dynamics of the turbidity maximum zone in a macrotidal estuary (the Gironde, France): Observations from field and MODIS satellite data. Estuarine, Coastal and Shelf Science 81, 321-332

Dyer K.R., Christie M.C. \& Manning A.J., 2004. The effects of suspended sediment on turbulence within an estuarine turbidity maximum, Estuarine, Coastal and Shelf Science 59, 237-248.

Fettweis M., Sas M. \& Monbaliu J., 1998. Seasonal, neap-spring and tidal variation of cohesive sediment concentration in the Scheldt estuary, Belgium. Estuarine Coastal Shelf Science 47, 21-36.

Friedrichs C.T. \& Aubrey D.G., 1994. Tidal propagation in strongly convergent channels. Journal of Geophysical Research 99 (C2), 3321-3336.

Garel E., Pinto L., Santos A. \& Ferreira O., 2009. Tidal and river discharge forcing upon water and sediment circulation at a rock-bound estuary (Guadiana estuary, Portugal). Estuarine, Coastal and Shelf Science 84, 269-281.

Geyer W.R., 1993. The importance of suppression of turbulence by stratification on the estuarine turbidity maximum. Estuaries, 16, No. 1, 113-125

Goff, J.R., 1997. A chronology of natural and anthropogenic influences on coastal sedimentation, New Zealand. Marine Geology 138(1/2), 105-117.

Grabemann I. \& Krause G., 1989. Transport processes of suspended matter derived from time series in a tidal estuary. Journal of Geophysical Research 94, No. C10, 14373-14379.

Green M.O. \& Hancock, 2012. Sediment Transport through a tidal creek. Estuarine, Coastal and Shelf Science 109, 116-132.

Hume T.M. \& McGlone M.S., 1986. Sedimentation patterns and catchment use changes recorded in the sediments of a shallow tidal creek, Lucas Creek, Upper Waitemata Harbour, New Zealand. Journal of the Royal Society of New Zealand 19, 305-317. 
Jalon-Rojas I., Schmidt S. \& Sottolichio A., 2015. Turbidity in the fluvial Gironde Estuary (southwest France) based on 10-year continuous monitoring: sensitivity to hydrological conditions. Hydrology and Earth Systems Sciences 19, 2805-2819.

Jiang X., Lu B. \& He Y., 2013. Response of the turbidity maximum zone to fluctuations in sediment discharge from river to estuary in the Changjiang Estuary (China). Estuarine, Coastal and Shelf Science 131, 24-30.

Li X., Zhu J., Yuan R., Qiu C. \& Wu H., 2016. Sediment trapping in the Changjiang Estuary: observations in the North Passage over a spring-neap tidal cycle. Estuarine, Coastal and Shelf Science, in press

Liu J.T., Hung J.-J. \& Huang Y.-W., 2009. Partition of suspended and riverbed sediments related to the salt wedge in the lower reaches of a small mountainous river. Marine Geology 264, 152-164.

McGlone M.S., 1983. Polynesian deforestation of New Zealand: a preliminary synthesis. Archaeology in Oceania 18, 11-25.

McSweeney J.M., Chant R.J. \& Sommerfield C.K., 2016. Lateral Variability of Sediment Transport in the Delaware Estuary. J. Geophysical Research Oceans 121, 725-744

Mitchell S.B., West J.R., Arundale A.M.W., Guymer I. \& Couperthwaite J.S., 1998. Dynamics of the turbidity maxima in the upper Humber estuary system. Marine Pollution Bulletin 37, 190-205.

Mitchell S.B., Couperthwaite J.S., West J.R. \& Lawler D.M., 2003. Measuring sediment exchange rates on an intertidal bank at Blacktoft, Humber Estuary, UK. Science of the Total Environment, 314-316, 535-549.

Mitchell S.B., Uncles R.J. \& Akesson L. 2012. Observations of turbidity in the Thames estuary. Water and Environment Journal 26, 511-520

Obrador B. \& Pretus J.L., 2008. Light regime and components of turbidity in a Mediterranean coastal lagoon. Estuarine, Coastal and Shelf Science 77, 123-133.

Page M.J. \& Trustrum N.A., 1997. A late Holocene lake sediment record of the erosion response to land use change in a steep catchment, New Zealand. Zeitschrift für Geomorphologie 41, 369-392.

Pedersen T.M., Gallegos C.L. \& Nielsen S.L., 2012. Influence of near-bottom re-suspended sediment on benthic light availability. Estuarine, Coastal and Shelf Science 106, 93-101.

Savoye N., David V., Morisseau F., Etcheber H., Abril G., Billy I., Charlier K., Oggian G., Derrienic H. \& Sautour B., 2012. Origin and composition of particulate organic matter in a macrotidal turbid estuary: The Gironde Estuary, France. Estuarine, Coastal and Shelf Science 108, 16-28.

Schuttelaars H.M., de Jonge V.N. \& Chernetsky A., 2013. Improving the predictive power when modelling the physical effects of human interventions in estuarine systems. Ocean and Coastal Management 79, 70-82.

Sommerfield C.K. \& Wong K.C., 2011. Mechanisms of sediment flux and turbidity maintenance in the Delaware Estuary, J. Geophysical Research (Oceans) 116, C01005, doi:10.1029/2010JC006462.

Uncles R.J. \& Stephens J.A., 1993. The freshwater-saltwater interface and its relationship to the turbidity maximum in the Tamar estuary, United Kingdom. Estuaries 16, No. 1, 126-141 
Uncles R.J., Barton M.L. \& Stephens J.A., 1994. Seasonal variability of fine-sediment concentrations in the turbidity maximum region of the Tamar estuary. Estuarine Coastal Shelf Science 38, 19-39

Uncles R.J., Stephens J.A. \& Smith R.E., 2002. The dependence of estuarine turbidity on tidal intrusion length, tidal range and residence time. Continental Shelf Research 22, 1835-1856

Uncles R.J., Stephens J.A. \& Harris C., 2006. Runoff and tidal influences on the estuarine turbidity maximum of a highly turbid system: The upper Humber and Ouse Estuary, UK. Marine Geology 235, 213228.

Wai O.W.H., Wang C.H., Li Y.S. \& Li X.D., 2004. The formation mechanisms of turbidity maximum in the Pearl River estuary, China. Marine Pollution Bulletin 48, 441-448.

Warner J.C., Sherwood C.R. \& Geyer W.R., 2007. Sensitivity of estuarine turbidity maximum to settling velocity, tidal mixing, and sediment supply, In: J.P.Y. Maa, L.P. Sanford and D.H. Schoellhamer, Editor(s), Proceedings in Marine Science, Elsevier, Volume 8, 355-376.

Wu J., Liu J.T., Shen H. \& Zhang S., 2004. Dispersion of disposed dredged slurry in the meso-tidal Changjiang (Yangtze River) Estuary. Estuarine, Coastal and Shelf Science 70, 663-672.

Wu J., Liu J.T. \& Wang X., 2012. Sediment trapping of turbidity maxima in the Changjiang Estuary. Marine Geology 303-306, 14-25

Xu F., Wang D-P. \& Riemer N., 2010. An idealised model study of flocculation on sediment trapping in an estuarine turbidity maximum. Continental Shelf Research 30, 1314-1323

\section{Figure captions}

Fig.1 - Map of study site.

Fig. 2 - Freshwater flow for early 2013 measured at the limit of the tidal influence of the Kaipara river. Circles indicate deployment days 19 Feb and 5 Mar. Source: Auckland Regional Council

Fig.3 - Velocity (m/s) (a), salinity (b) and SSC (g/l) (c) over time at KW 19 Feb 2013, for a whole tidal cycle. Positive current velocity in $\mathrm{m} / \mathrm{s}$ (yellow shades) denotes down-estuary (seawards) flow, and negative (blue shades) denotes up-estuary (landwards) flow. Time (in hours, local) along the horizontal axis with vertical distance from the bed up the vertical axis in all plots.

Fig.4 - Velocity (m/s) (a), salinity (b) and SSC (g/l) (c) over time at HB 19 Feb 2013, for a whole tidal cycle. Positive current velocity (yellow shades) denotes down-estuary (seawards) flow, and negative (blue shades) denotes up-estuary (landwards) flow. Time (in hours, local) along the horizontal axis with vertical distance from the bed up the vertical axis in all plots.

Fig.5 - Longitudinal depth mean salinity (a) and SSC (g/l) (b) 5 Mar 2013. Each line is labelled with time (in hours) relative to low water. Horizontal axis shows distance along the estuary measured from HB, positive indicates downstream (towards the sea) 
Fig.6 - Depth mean SSC (g/l) vs depth mean velocity (m/s) showing asymmetric behaviour between flood and ebb, on different dates as shown. Ebb current shown as positive.

Fig.7 - Estimate of total cumulative flux of material per unit width $\left(\mathrm{kg} \mathrm{m}^{-1} \mathrm{~s}^{-1}\right)$ at $\mathrm{KW}$ (a) and $\mathrm{HB}(\mathrm{b})$; positive flux seawards.

Fig.8 - Velocity (m/s) (a), salinity (b) and SSC (g/l) (c) over time at KW 4 July 2013 for 7 hours mainly encompassing the ebb tide during daylight. Positive current velocity in $\mathrm{m} / \mathrm{s}$ (yellow shades) denotes downestuary (seawards) flow, and negative (blue shades) denotes up-estuary (landwards) flow. Time (in hours, local) along the horizontal axis with vertical distance from the bed up the vertical axis in all plots.

Fig.9 - Velocity (m/s) (a), salinity (b) and SSC (g/l) (c) over time at HB 4 July 2013 for 7 hours mainly encompassing the ebb tide during daylight. Positive current velocity in $\mathrm{m} / \mathrm{s}$ (yellow shades) denotes downestuary (seawards) flow, and negative (blue shades) denotes up-estuary (landwards) flow. Time (in hours, local) along the horizontal axis with vertical distance from the bed up the vertical axis in all plots. 
FIG 1
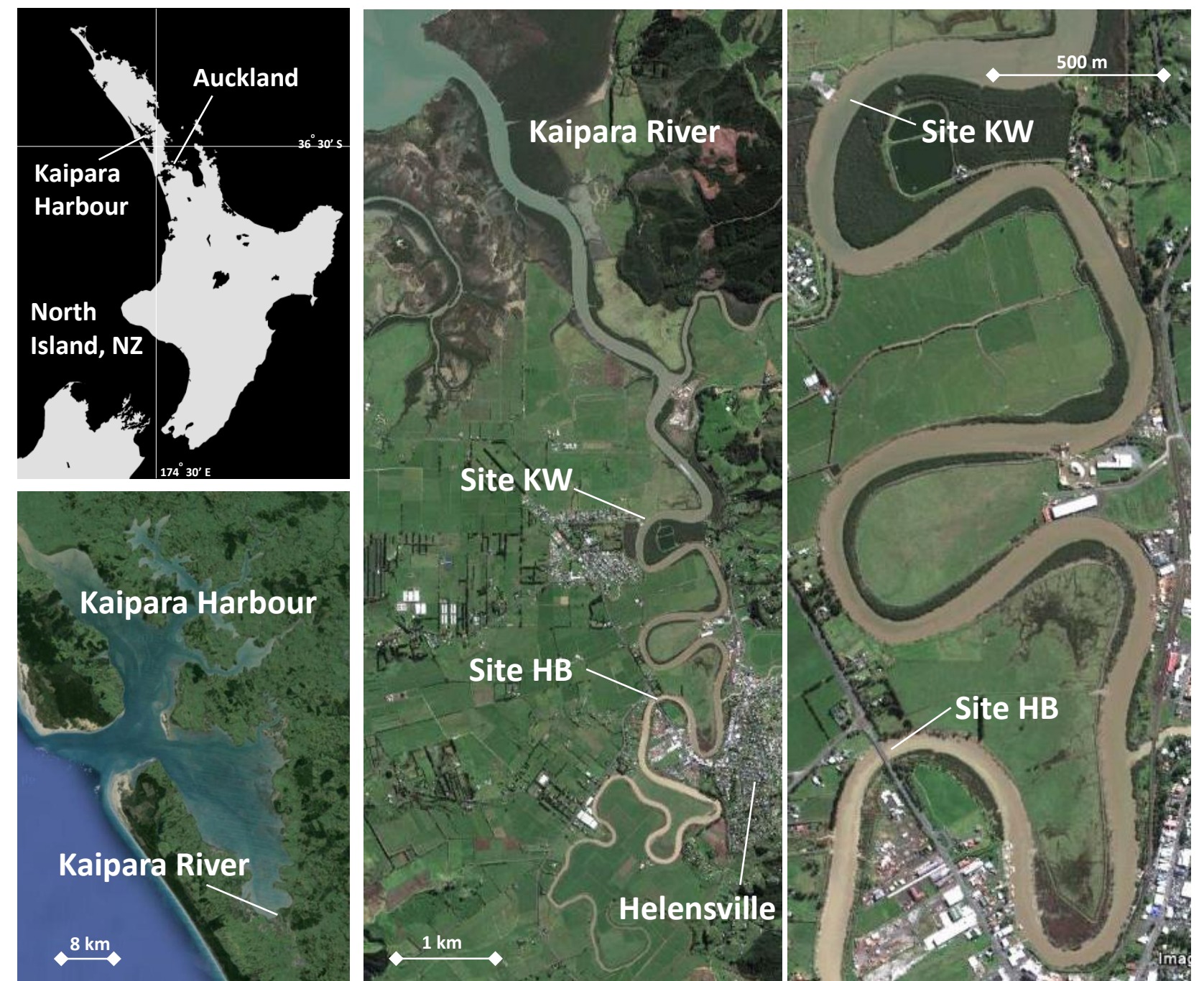

(s)
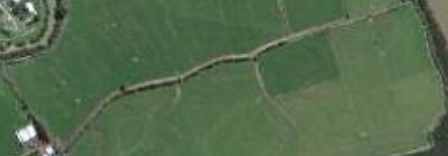

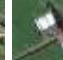
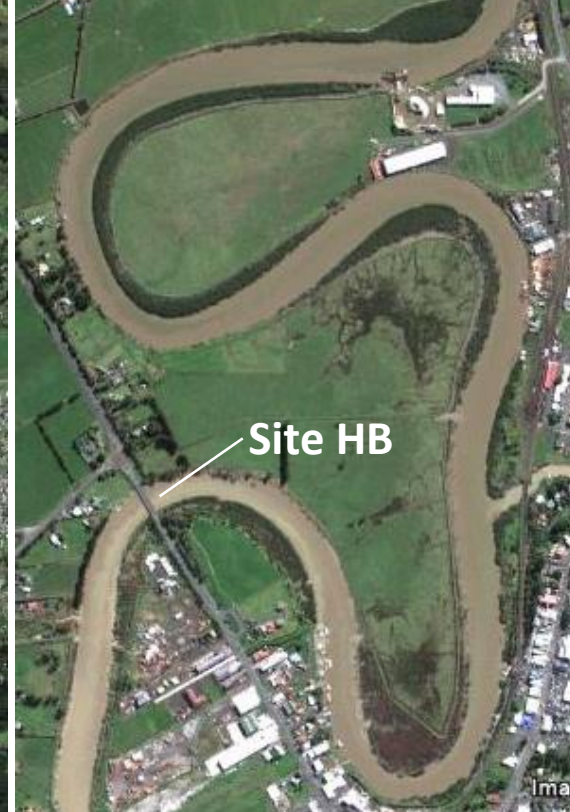
FIG 2

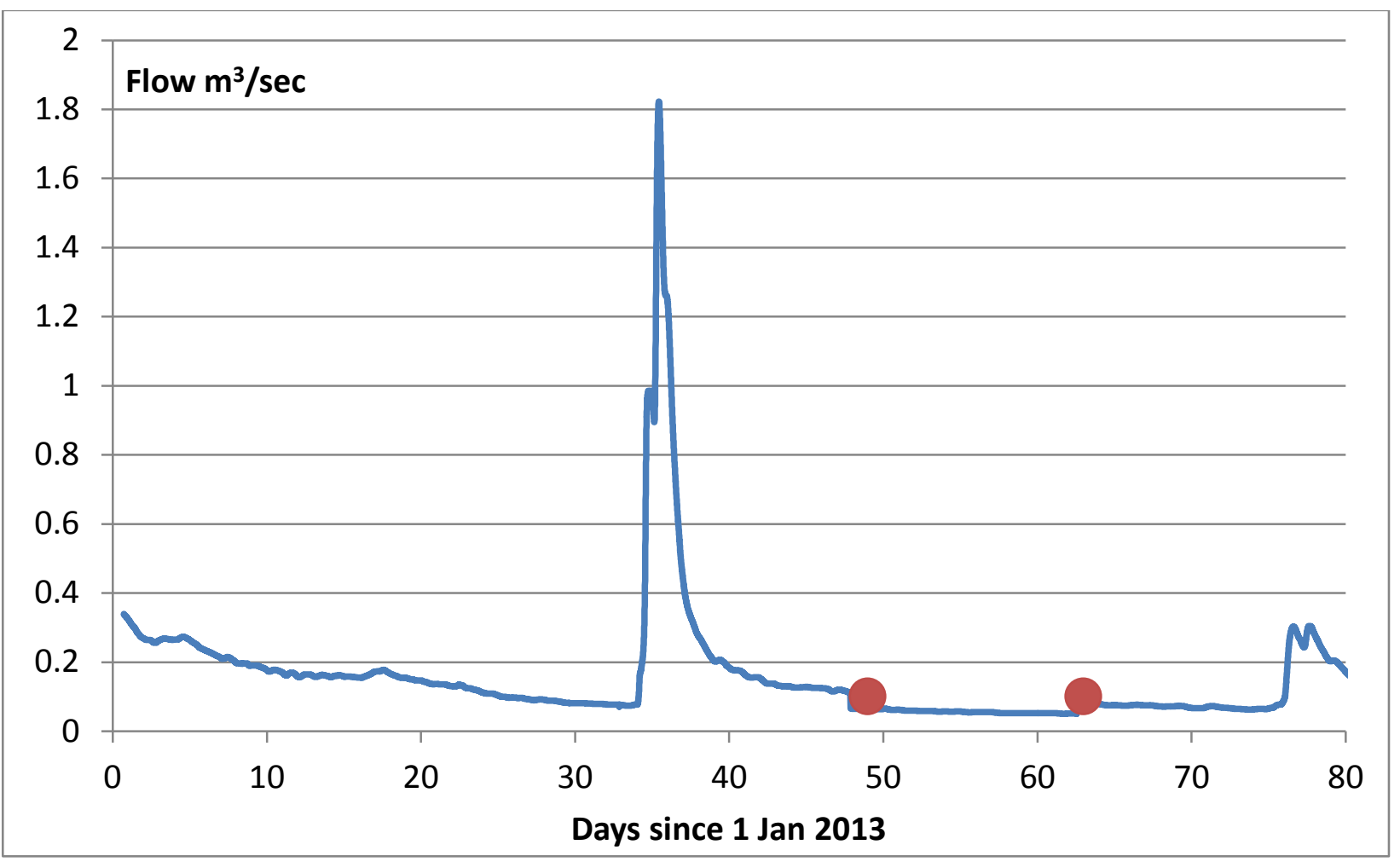




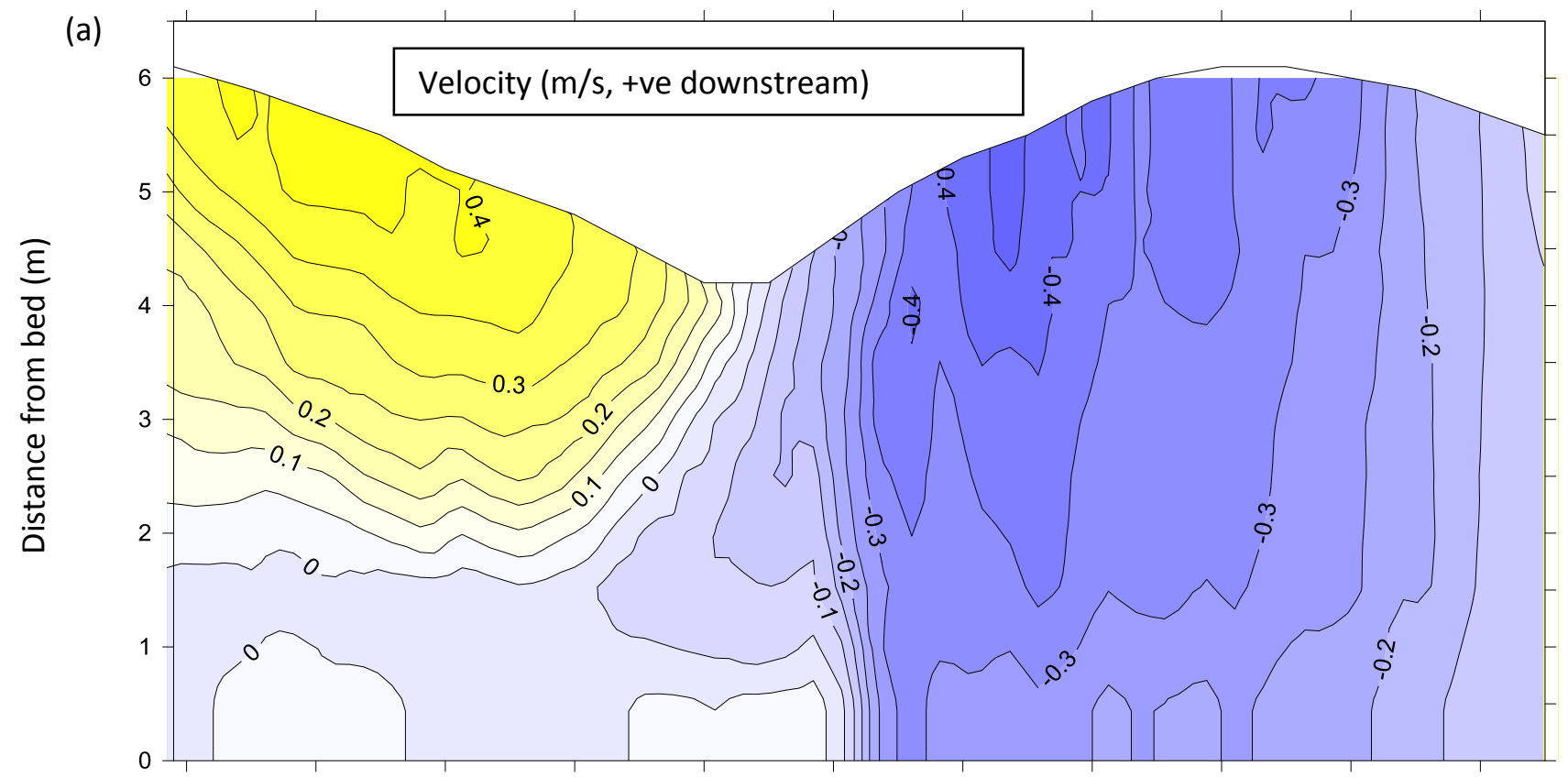

(b)
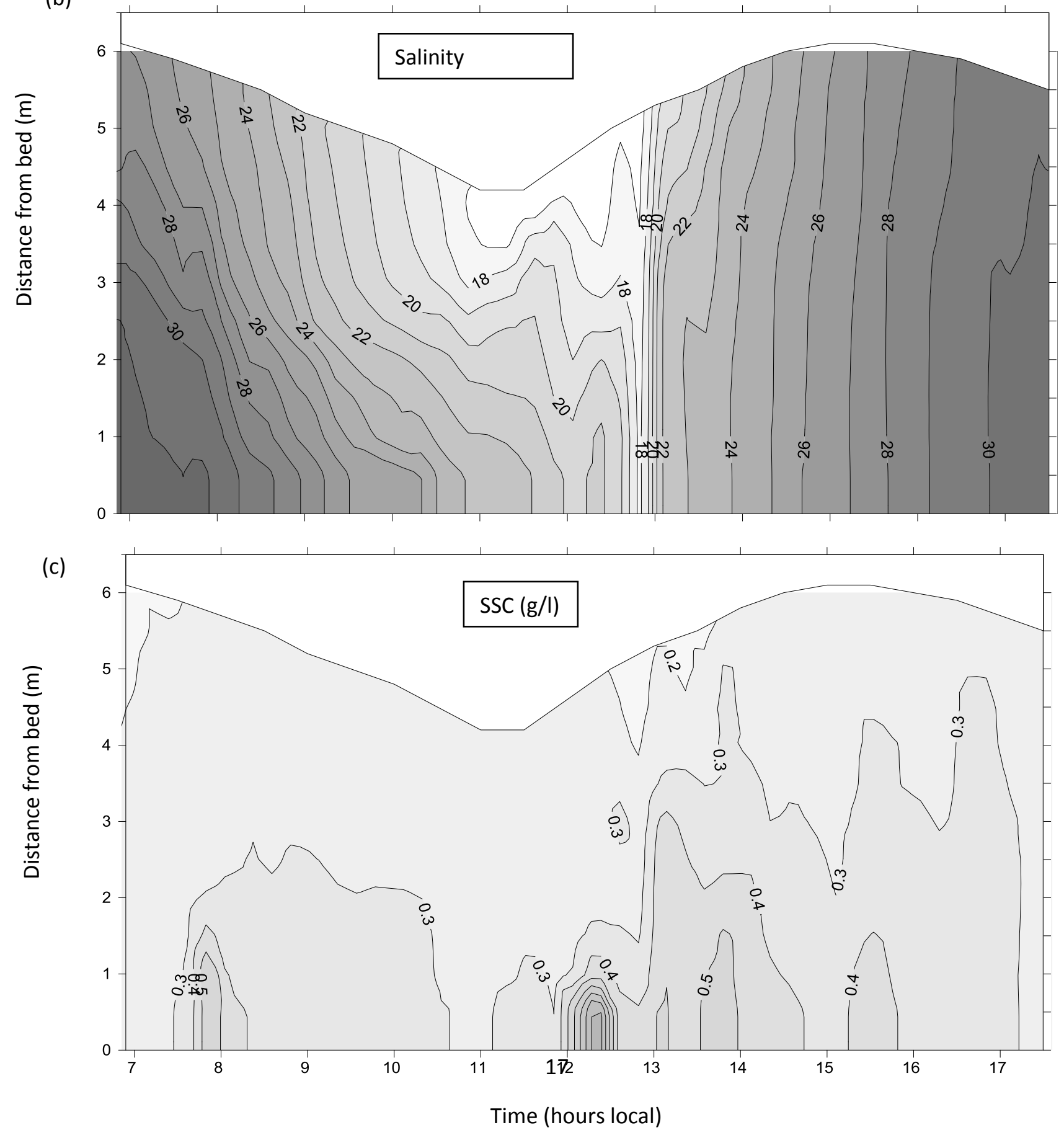
Fig 4

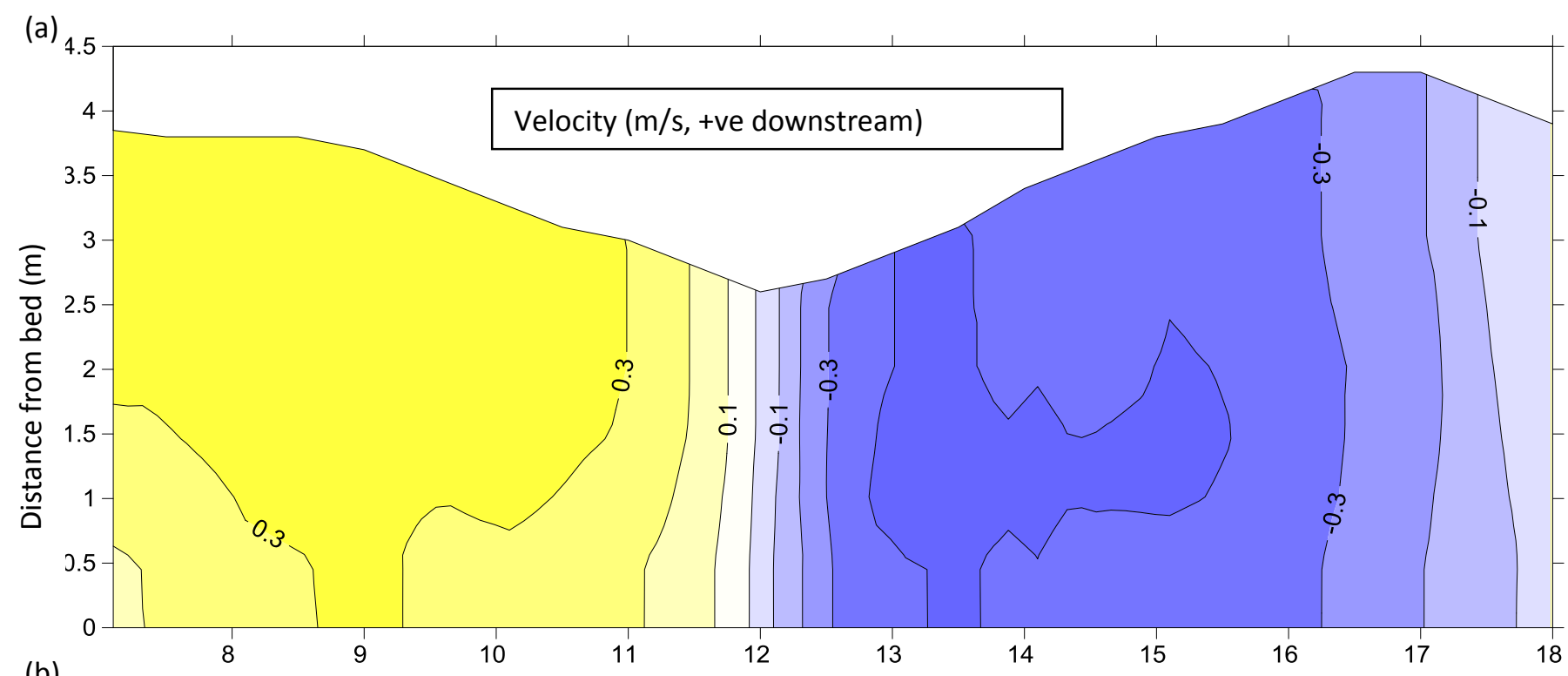

(b)

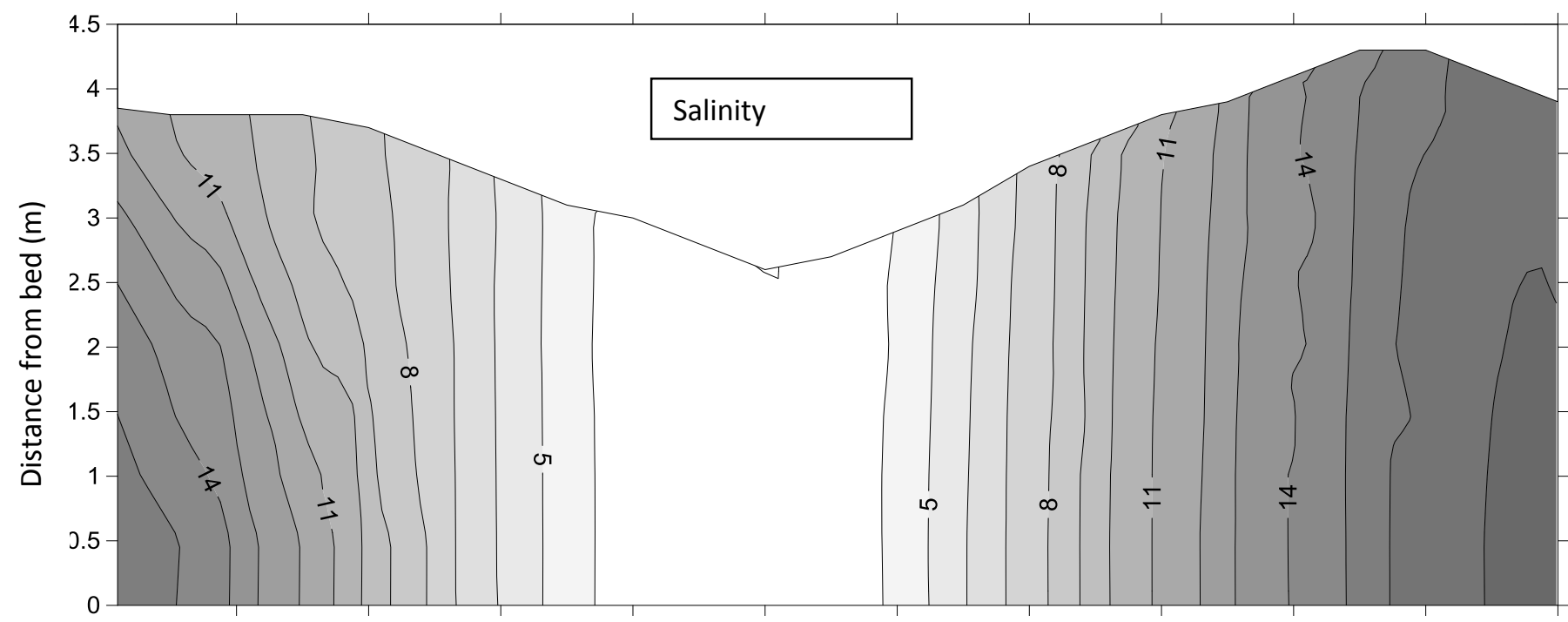

(c)

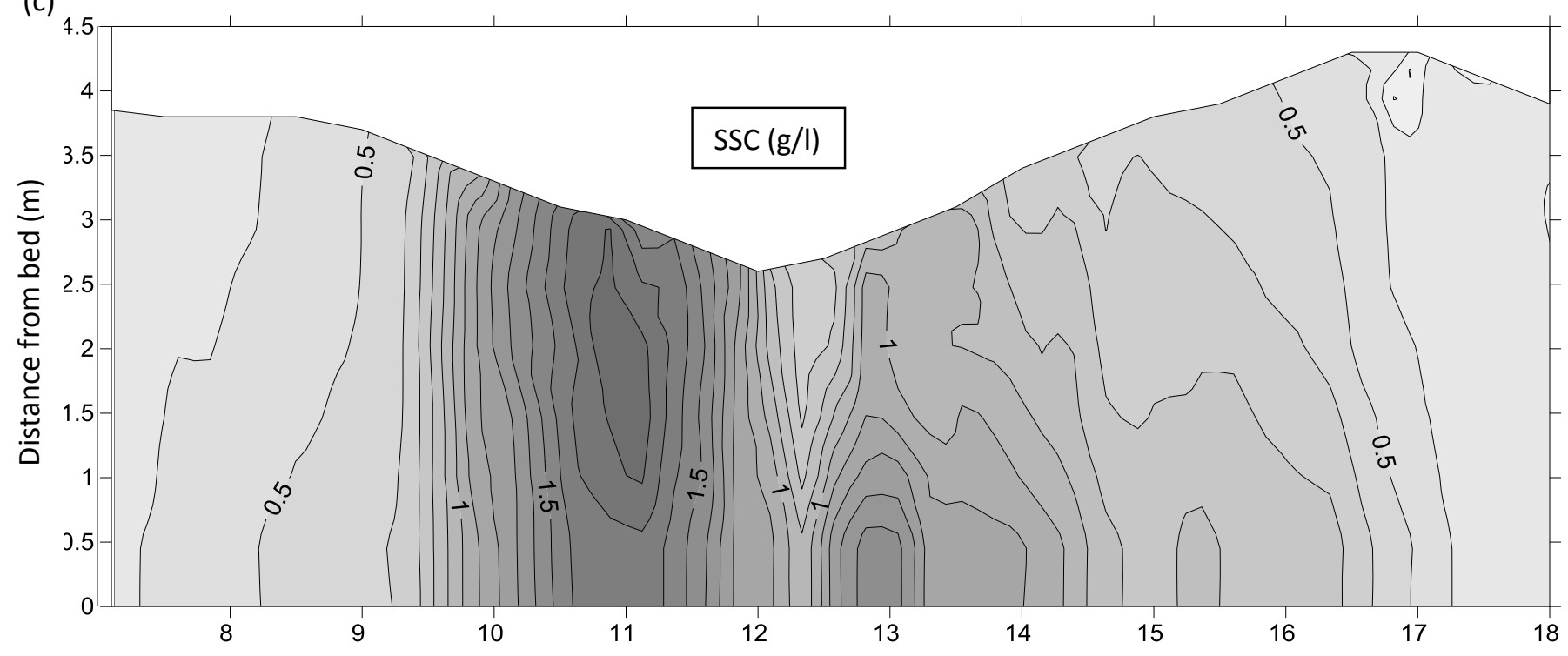

Time (hours local) 
FIG 5

(a)

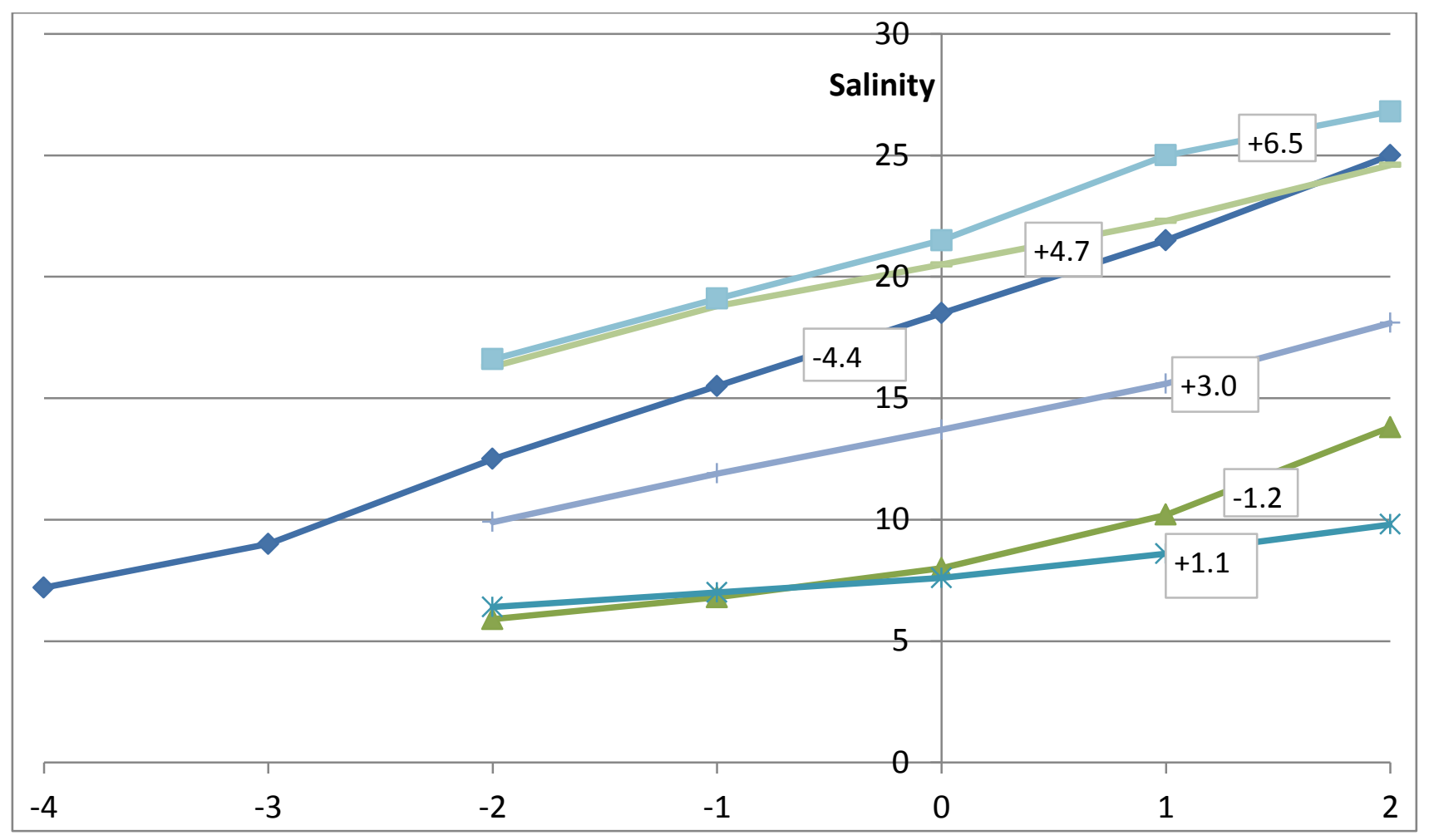

(b)

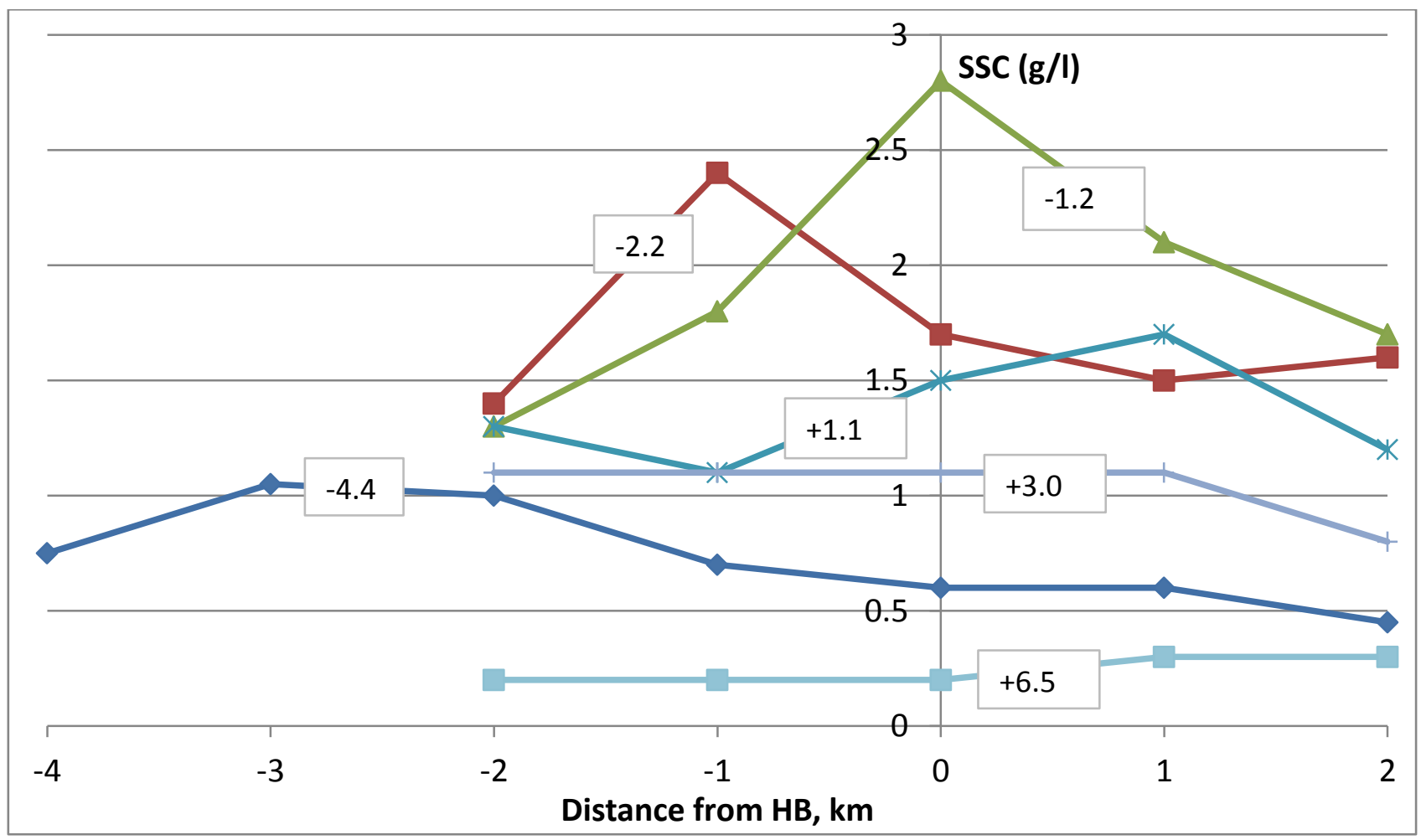


FIG 6

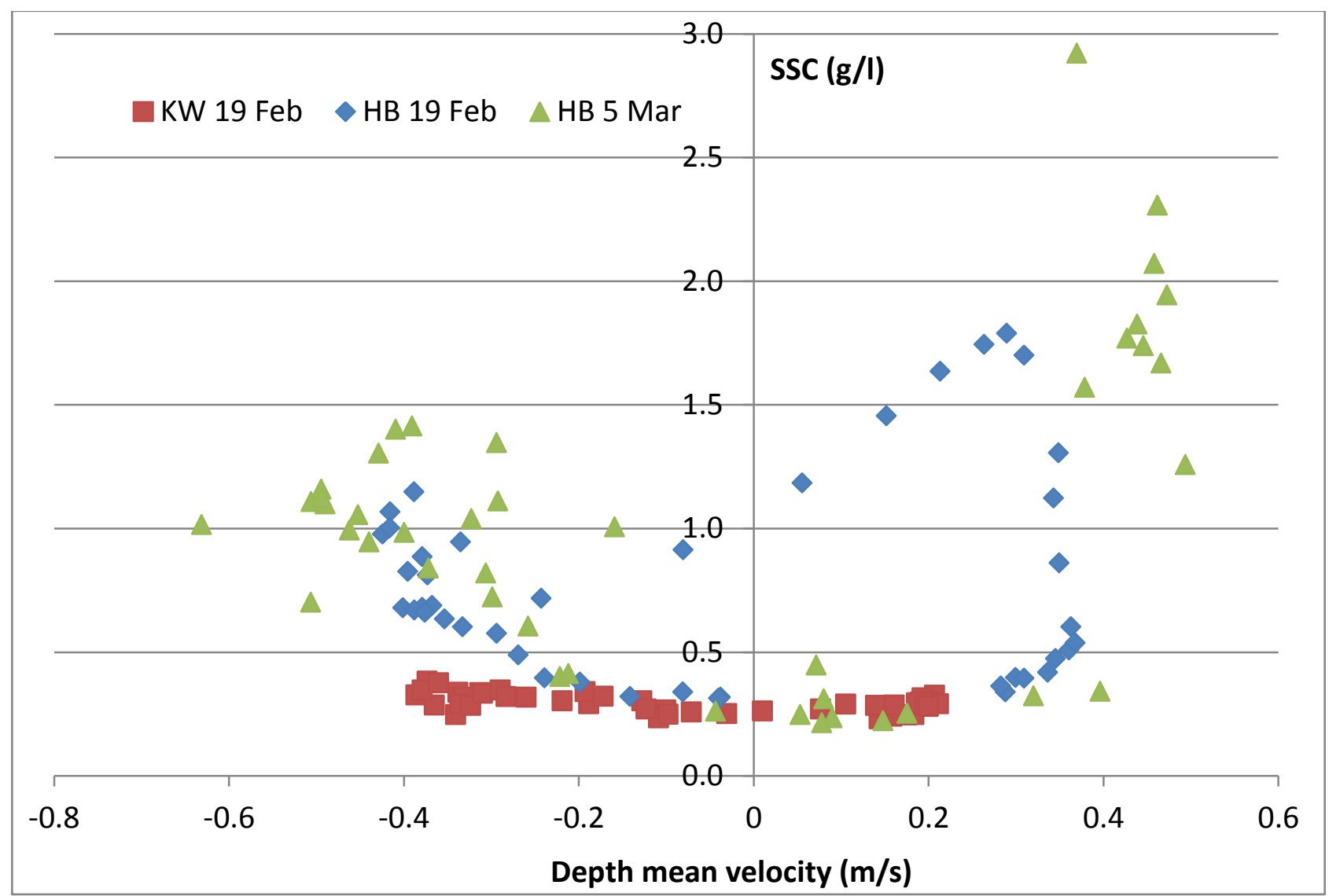




\section{FIG 7}

(a)

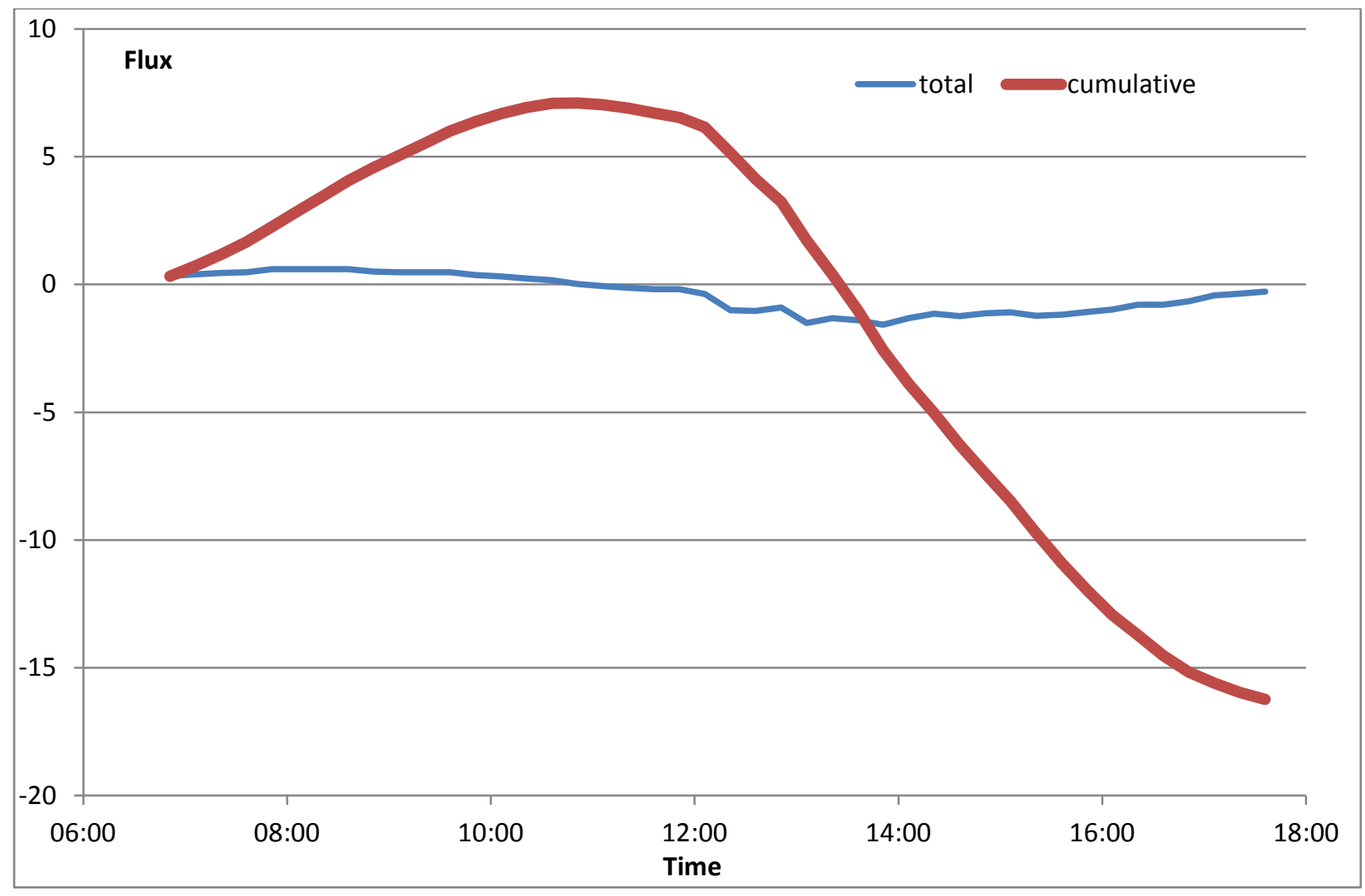

(b)

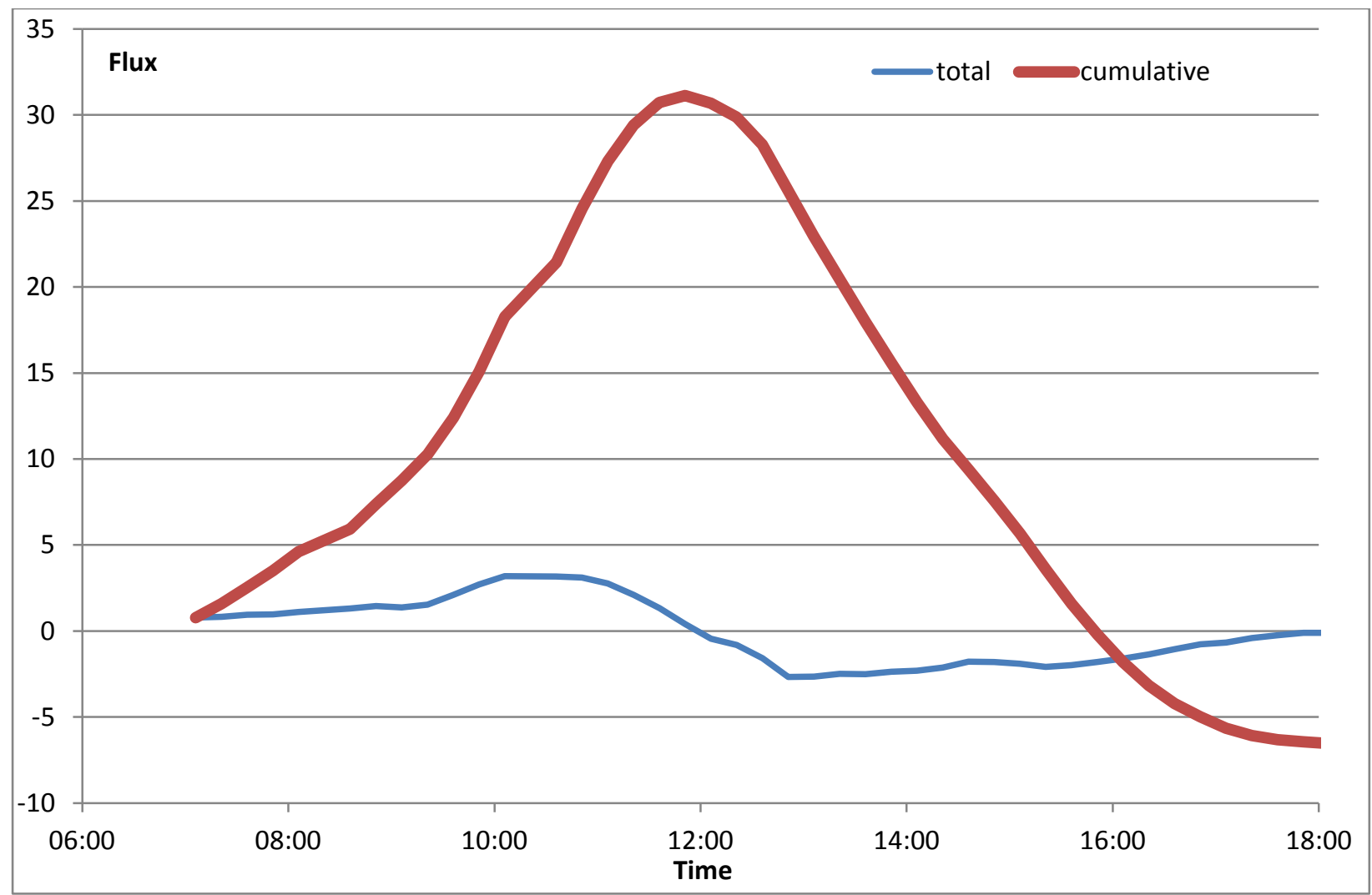




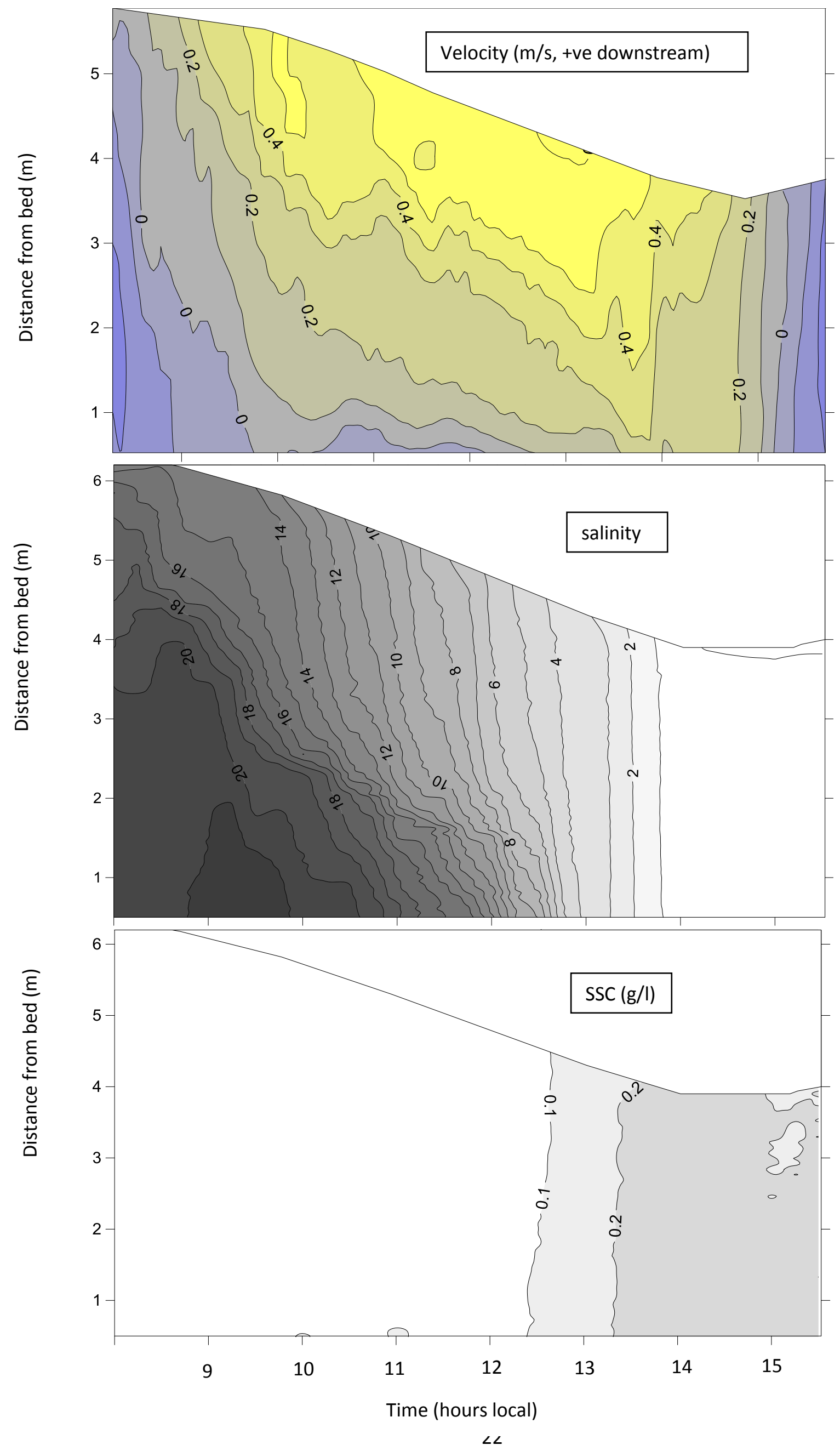



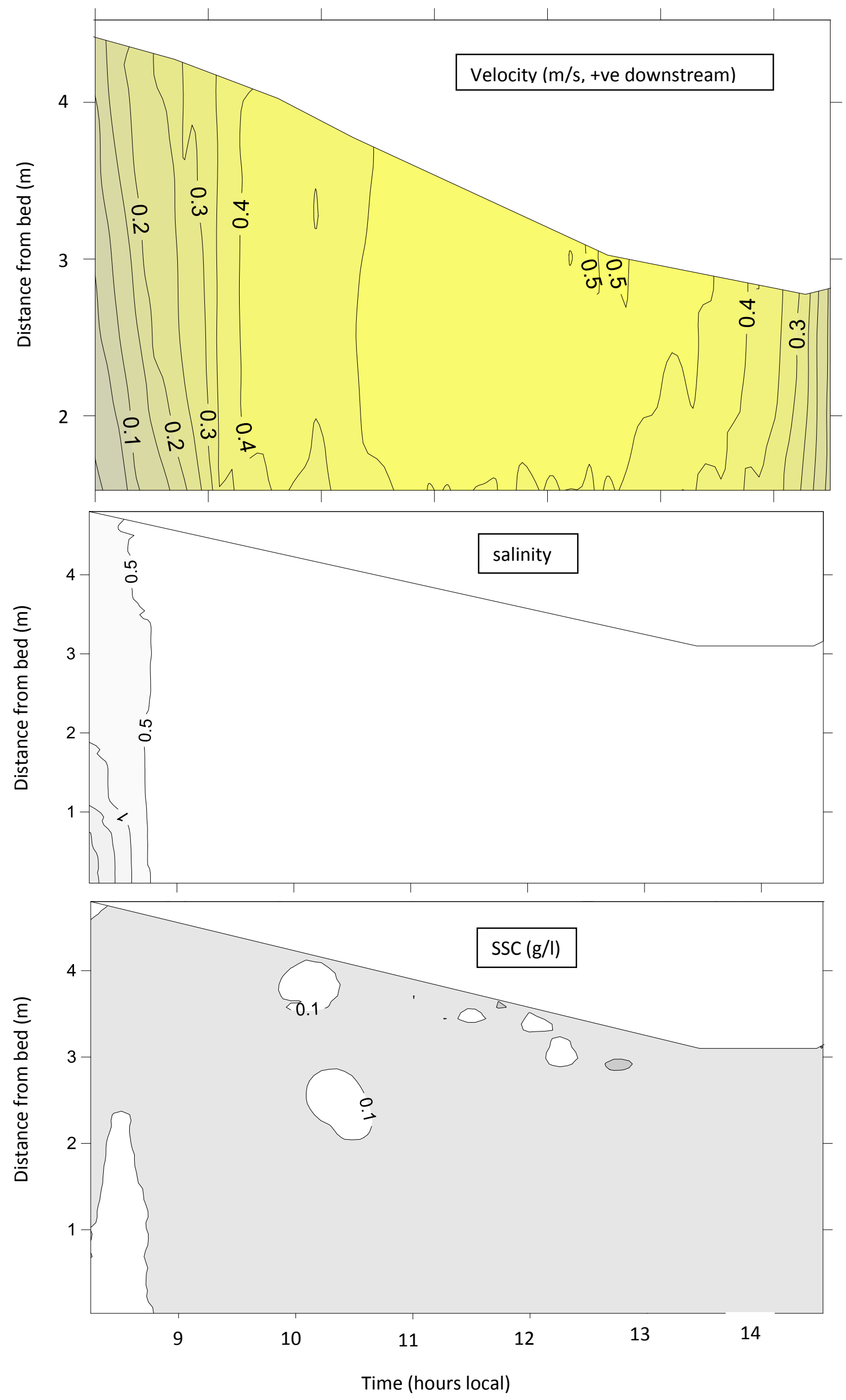